\title{
Response to Heard et al
}

\author{
Maryline Moulin ${ }^{1}$, Anne K Voss ${ }^{2,3}$, Tim Thomas ${ }^{2,3}$, Wendy Wei-Lynn Wong ${ }^{4}$, Wendy D Cook ${ }^{5}$, \\ Frank Koentgen ${ }^{6}$, James Vince ${ }^{2,3}$, John Silke ${ }^{2,3}$ \& David L Vaux ${ }^{2,3}$
}

Reply to: KN Heard et al (in this issue)

$\mathrm{H}$ eard et al (2015) generated clap1 $^{-/-}$ $\mathrm{Xiap}^{-1-}$ mice and were surprised to find them to be viable and fertile, because we had reported (Moulin et al, 2012) that clap $^{-1-} \mathrm{Xiap}^{-/-}$mice died by day E12.5 of embryogenesis (Moulin et al, 2012 Figs 1B and 2B and Supplementary Fig S1A). We are working with Heard et al (2015) in an attempt to determine why.

It is, however, clear that failure of our

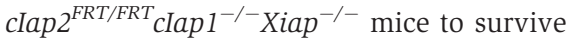
past E12.5 is not due to non-functional clap $^{-/-}$genes. Three types of cross indicate that the $\operatorname{CIAp} 2^{F R T / F R T}$ locus, which is carried by our $\mathrm{clap}^{-/-}$mice, does produce functional cIAP2. Firstly, comparison of the phenotypes of the $\operatorname{CIAp} 2^{\text {FRT/FRT }}$ CIAP $1^{-/-}$mice, which are viable and fertile, with the clap $2^{-1-}$ clap $^{-1-}$ mice, which die at E12.5, indicates that the $\operatorname{CIap} 2^{F R T / F R T}$ locus can function, at least to the extent needed to allow normal development when Xiap is present (Moulin et al, 2012). Secondly, when specific deletion of clap1 in B cells was combined with whole body cIap2 deletion, it led to more profound B-cell expansion than deletion of either IAP alone (Gardam et al, 2011). Thirdly, deletion of clap1 in myeloid cells on either a cIap2 $2^{-/-}$or clap2 $^{-/-}$ $\mathrm{Xiap}^{-/-}$background triggered splenomegaly, increased neutrophils and monocytes, inflammatory cytokine production and spontaneous inflammatory arthritis, whereas deletion of Xiap, cIap1 or clap2 alone did not (Wong et al, 2014; Lawlor et al, 2015).

In addition to the differences in viability of the clap $^{-/-} \mathrm{Xiap}^{-/-}$mice, Heard et al (2015) found much higher levels of cIAP2 protein in their clap1 $1^{-/-}$mouse embryonic fibroblasts (MEFs) than we reported in our cIap $1^{-/-}$MEFs. Furthermore, Heard et al (2015) confirmed this difference: when they directly compared our cIap1 $^{-/-}$MEFs with

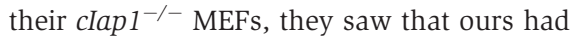
very low to undetectable levels of cIAP2 protein (like wild-type MEFs), whereas theirs had much higher levels of cIAP2 (Fig 1F, compare lanes 1, 2 and 4).

Consistent with their finding that levels of cIAP2 rise in the absence of cIAP1 in MEFs, they also found elevated levels of cIAP2 protein in several tissues of cIap $^{-/-}$ $\mathrm{Xiap}^{-/-}$mice.

Although we did not observe elevated CIAP2 in our $\operatorname{CIap} 2^{\text {FRT/FRT }}$ CIAP1 $^{-/-}$MEFs, their finding of increased cIAP2 in their $\mathrm{CIap1}^{-/-}$ MEFs is consistent with data from several laboratories (including our own) showing that absence or depletion of cIAP1 leads to activation of non-canonical NF- $\mathrm{KB}$ and cIAP2 up-regulation (Varfolomeev et al, 2007; Vince et al, 2007; Darding et al, 2011). Indeed, as Heard et al (2015) show, our cIap2 $2^{\text {FRT/FRT }}$ cIap1 $1^{-/-}$MEFs have elevated cIap2 mRNA expression when compared with their cIap $1^{\text {loxP/loxP }}$ cIap2 $2^{\text {FRT/FRT, }}$ cIAP1-proficient counterparts. This indicates a potential defect in translation or stability of the cIAP2 protein in our MEFs.

Note, however, that in our hands, immortalised MEFs are highly genetically variable, with a tendency to lose the expression of proteins, often seemingly at random (Cook et al, 2014). Thus, it remains possible that the particular line of immortalised MEFs that we shared with Heard et al (2015) are not truly representative of the situation elsewhere in the mice.
Why might MEFs derived from our clap2 $2^{\text {FRT/FRT }}$ CIap $^{-/-}$and clap2 $2^{\text {FRT/FRT }}$ CIap $^{-/-}$ $\mathrm{Xiap}^{-1-}$ mice have much lower levels of cIAP2 than the MEFs from their CIap1 $^{-/-}$and

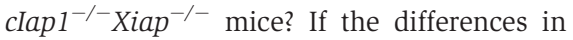
cIAP2 levels in the MEFs are reflected in vivo,

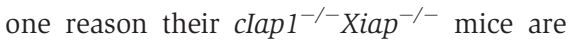
viable, whereas our cIap $1^{-/-} \mathrm{Xiap}^{-/-}$mice die in mid-embryogenesis, might be differing levels of cIAP2 present during embryogenesis. In a number of molecular pathways minimum threshold levels of protein are required for normal development. As we have only observed one morphological anomaly, namely defects in the integrity of the atrial walls of the heart (Moulin et al, 2012), it is possible that in one experimental system there is enough IAP2 protein to avoid this lethal defect, whereas in another there is not. Furthermore, if this is the case, is the amount of cIAP2 aberrantly low in our mice, or is it aberrantly high in theirs, or both?

If there are differences in the production of cIAP2 protein, it might be due to the way the closely linked cIap1 locus was deleted in each of the strains. Heard et al (2015) used clap $^{-/-}$mice as described in Conze et al (2005). These were generated from 129/Sv E14 embryonic stem (ES) cells by homologous recombination of a neomycin (Neo) resistance gene in reverse orientation in place of the transcription initiation start codon and the first BIR domain of cIap1 (see Fig 1A of Conze et al, 2005). These mice were backcrossed to C57BL/6 mice for multiple generations. We generated cIap2 $2^{\text {FRT/FRT }} \operatorname{cIap} 1^{\text {loxP/loxP }}$ mice by sequentially targeting the same chromosome in BRUCE embryonic stem cells, which were derived from C57BL/6 mice (Koentgen et al,

\footnotetext{
1 INSERM 1180, Université Paris Sud, Paris, France

2 The Walter and Eliza Hall Institute, Parkville, Vic., Australia. E-mail: vaux@wehi.edu.au

3 Department of Medical Biology, The University of Melbourne, Parkville, Vic., Australia

4 Institute of Experimental Immunology, University of Zürich, Zürich, Switzerland

5 La Trobe Institute for Molecular Sciences, La Trobe University, Bundoora, Vic., Australia

6 Ozgene Pty Ltd, Bentley DC, WA, Australia

DOI 10.15252/embj.201592761
} 
1993). In these mice, an FRT site is inserted $5^{\prime}$ of the ATG of cIap2, and an FRT-flanked $\mathrm{Neo}$ gene is inserted into the intron between exons 3 and 4 (see Fig $1 \mathrm{~A}$ of Moulin et al, 2012).

Because the clap2 gene is so close to the clap1 gene, in some circumstances, the Neo gene or the promoter driving it in Heard

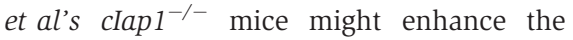
expression of the linked clap2 gene, or it is possible that clap2 regulatory sequences were inadvertently altered during homologous recombination. On the other hand, in our clap2 $2^{\text {FRT/FRT }}$ Clap $^{-/-}$mice, it is possible that the intronic Neo gene and Pgk promoter sometimes decrease the expression of clap2 or the efficiency with which its mRNA is spliced.

Another possible explanation for the differences between the two sets of $\mathrm{clap1}^{-/-}$ $\mathrm{Xiap}^{-/-}$mice is the presence or absence of $129 /$ Sv versus C57BL/6 polymorphic genes, especially those physically linked to the clap2-cIap1 locus. In our mice, the genes are of $\mathrm{C} 57 \mathrm{BL} / 6$ origin, as the mice were generated from C57BL/6 BRUCE ES cells, whereas even with extensive backcrossing, the genes linked to the cIap2-cIap1 locus in Heard et al's mice will be of $129 / \mathrm{Sv}$ origin. In addition to the mutation in caspase-11 already described (Kenneth et al, 2012), there is a very high probability that the Mmp1a gene is also mutated in these strains of mice (Vanden Berghe et al, 2015). We know that even minor differences in the expression of other genes can have a major effect on the

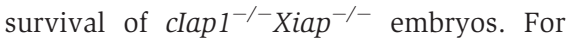
example, when we crossed our clap $^{-/-}$ $\mathrm{Xiap}^{-/-}$mice onto a heterozygous Ripk1 ${ }^{+/-}$ background, rather than dying at E12.5, some survived until weaning (Moulin et al, 2012, Fig 6C and Supplementary Fig S3).

There are several lines of experimentation that might reveal why Heard et al's

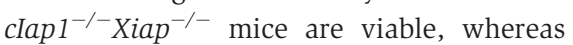

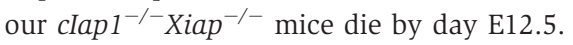

Sequencing the cIap1-cIap2 locus in the two clap $1^{-/-}$lines might reveal unexpected changes in the parental $\operatorname{cIap2} 2^{F R T / F R T} \mathrm{CIAp}^{-/-}$ or CIap $^{-/-}$mice. Using CRISPR/Cas9 technology to mutate the $\operatorname{clap} 1^{-/-}$gene in cell lines or C57BL/ 6 zygotes might show if our $\operatorname{cIap} 2^{\text {FRT/FRT }}$ CIap $1^{-/-}$mice have aberrantly low levels of cIAP2, or their $\operatorname{cIap1}^{-/-}$ mice have aberrantly high levels of cIAP2. These mice could be crossed with Xiap ${ }^{-1-}$ knockouts to test their viability. We welcome any other suggestions for experiments and are happy to provide mice or cell lines to other investigators.

\section{References}

Conze DB, Albert L, Ferrick DA, Goeddel DV, Yeh WC, Mak T, Ashwell JD (2005)

Posttranscriptional downregulation of C-IAP2 by the ubiquitin protein ligase C-IAP1 in vivo. Mol Cell Biol 25: 3348-3356

Cook WD, Moujalled DM, Ralph TJ, Lock P, Young SN, Murphy JM, Vaux DL (2014) RIPK1- and RIPK3-induced cell death mode is determined by target availability. Cell Death Differ 21: $1600-1612$

Darding M, Feltham R, Tenev T, Bianchi K, Benetatos C, Silke J, Meier P (2011) Molecular determinants of Smac mimetic induced degradation of CIAP1 and CIAP2. Cell Death Differ 18: $1376-1386$

Gardam S, Turner VM, Carter H, Limaye S, Basten A, Koentgen F, Vaux DL, Silke J, Brink R (2011) Deletion of CIAP1 and CIAP2 in B lymphocytes constitutively activates cell survival pathways and inactivates the germinal center response. Blood 117: 4041 - 4051

Heard KN, Bertrand MJM, Barker PA (2015) CIAP2 supports viability of mice lacking CIAP1 and XIAP. EMBO J 34: 2393-2395

Kenneth NS, Younger JM, Hughes ED, Marcotte D, Barker PA, Saunders TL, Duckett CS (2012) An inactivating caspase 11 passenger mutation originating from the 129 murine strain in mice targeted for c-IAP1. Biochem J 443: $355-359$
Koentgen F, Suss G, Stewart C, Steinmetz M, Bluethmann $\mathrm{H}$ (1993) Targeted disruption of the Mhc class-li Aa gene in C57bl/6 mice. Int Immunol 5: 957-964

Lawlor KE, Khan N, Mildenhall A, Gerlic M, Croker BA, D’Cruz AA, Hall C, Kaur Spall S, Anderton H, Masters SL, Rashidi M, Wicks IP, Alexander WS, Mitsuuchi Y, Benetatos CA, Condon SM, Wong WW, Silke J, Vaux DL, Vince JE (2015) RIPK3 promotes cell death and NLRP3 inflammasome activation in the absence of MLKL. Nat Commun 6: 6282

Moulin M, Anderton H, Voss AK, Thomas T, Wong WW, Bankovacki A, Feltham R, Chau D, Cook WD, Silke J, Vaux DL (2012) IAPs limit activation of RIP kinases by TNF receptor 1 during development. EMBO J 31: 1679-1691

Vanden Berghe T, Hulpiau P, Martens L, Vandenbroucke RE, Van Wonterghem E, Perry SW, Bruggeman I, Divert T, Choi SM, Vuylsteke M, Shestopalov VI, Libert C, Vandenabeele P (2015) Passenger mutations confound interpretation of all congenic knockout mice. Immunity 43: 200-209

Varfolomeev E, Blankenship JW, Wayson SM, Fedorova AV, Kayagaki N, Garg P, Zobel K, Dynek JN, Elliott LO, Wallweber HJ, Flygare JA, Fairbrother WJ, Deshayes K, Dixit VM, Vucic D (2007) IAP antagonists induce autoubiquitination of c-IAPs, NF-kappaB activation, and TNFalpha-dependent apoptosis. Cell 131: 669-681

Vince JE, Wong WW, Khan N, Feltham R, Chau D, Ahmed AU, Benetatos CA, Chunduru SK, Condon SM, McKinlay M, Brink R, Leverkus $M$, Tergaonkar V, Schneider P, Callus BA, Koentgen F, Vaux DL, Silke J (2007) IAP antagonists target CIAP1 to induce TNFalpha-dependent apoptosis Cell 131: $682-693$

Wong WW, Vince JE, Lalaoui N, Lawlor KE, Chau D, Bankovacki A, Anderton H, Metcalf D, O’Reilly L, Jost PJ, Murphy JM, Alexander WS, Strasser A, Vaux DL, Silke J (2014) cIAPs and XIAP regulate myelopoiesis through cytokine production in an RIPK1- and RIPK3-dependent manner. Blood 123: $2562-2572$ 